\title{
Directive Speech Acts: a Cross-Cultural Study
}

\author{
Astghik Chubaryan \\ Lilit Sargsyan \\ Yerevan State University
}

$\mathrm{T}$ here are different modes of linguistic interaction between people. They depend on the feelings and intentions the interlocutors have at the moment of speech as well as on the fact who they are - both as individuals and as representatives of a particular cultural group/discourse community. Hence, every language makes available to the user the same basic set of speech acts, such as requesting, apologizing, declaring, and promising, with the exception of certain culture-specific ritualized acts such as baptizing, doubling at bridge, and excommunicating. Thus, if the English language permits such basic everyday acts as requesting, ordering, advising, suggesting, and warning, Armenian will too.

The main aim of the given paper is to give a comprehensive treatment of directive speech acts as culture-bound phenomena, namely from the point of view of different cultural values and norms, such as, for instance, intimacy vs. distance, directness vs. indirectness, politeness and courtesy vs. impoliteness, etc.

Intimacy implies an especially close personal relationship between the speaker and the addressee; and it is a well-known fact that English isn't particularly rich in devices to convey that. As Wierzbicka justly puts it (2003:47), the very absence of an intimate T-form of address, which sets English apart from many other languages (French: tu/vous; Russian: ты/вы; Armenian: nnı/пnıр, etc.), is a reflex of the same attitude. In fact, Anglo-Saxon culture seems to give preference to an utterly different value, i.e. distance. Thus, for instance, as compared to Armenian culture, where distance is viewed in the negative light, in Anglo-Saxon culture non-sexual body contact is heavily restricted: people seldom touch, kiss or hug one another, even hand-shaking is rather rare. They also keep at a considerable distance from each other. This culturally expected psychological distance between individuals testifies to the general need for psychological and physical privacy. It is these culture-specific values of distance and privacy that underlie a typically Anglo-Saxon cultural tradition, namely the emphasis on the rights and autonomy of every individual and the respect for everybody's selfdetermination. This is the reason why, despite the fact that the English language provides its speakers with explicit, direct ways for achieving communicative ends, the Anglo-Saxon speakers seem to prefer indirect ways. Unlike the Armenian culture, in the Anglo-Saxon culture directness is normally thought to bring to open confrontation, which indeed will disrupt social harmony. In other words, it is this Anglo-Saxon cultural assumption, commonly associated with the requirements of politeness, that underlies the heavy restrictions on the use of the imperative in English directive speech acts. Unlike English, in Armenian the bare imperative is used on a much wider scale.

However paradoxical it may seem, English warnings found on medicine labels are 
normally in the imperative, whereas in Armenian, warnings found on medicine labels are expressed by the infinitive form of the verb. Thus, for instance:

Keep out of the reach of children.

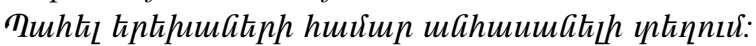
Do not use the product after the expiry date.

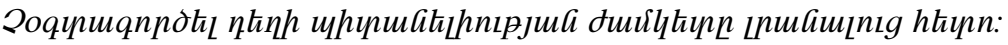

Now, how is this phenomenon to be accounted for? In fact, warnings of this type, just as advertisements and recipes, are public speech acts; first, they are anonymous, and, second, they are not directed at a particular addressee, but rather at an imaginary addressee. Therefore, the danger of being impolite does not arise, and the imperative is widely used without being offensive.

As for Armenian, the infinitive is used for almost the same reason as the imperative in English, i.e. the speech act is not directed to a particular person, but what is said in the warning concerns anybody who will buy the product. Thus, we witness how two different cultures and two different languages approach one and the same problem.

Likewise, in Armenian, side by side with the imperative, forms with the verb in the indicative mood are used to issue orders and commands. Below are two such examples taken from the Armenian soap opera "Anna":

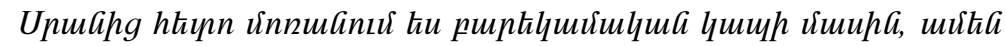

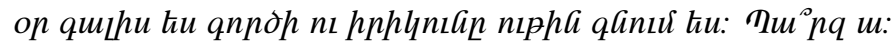

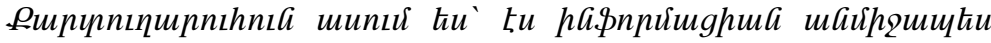

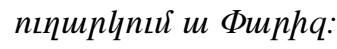

In this connection, it is to be noted that the commonly accepted and normally expected form for orders and commands both in English and Armenian is the imperative. However, unlike English, in Armenian we often find orders and commands expressed by means of a second-person predicate in the present indicative. Now, how is this phenomenon to be accounted for? In fact, the use of a given mood is congruent with the mentioned culture-specific attitudes. Namely, the imperative mood presupposes a possible future action on the part of the addressee. Hence the Anglo-Saxon speaker makes use of the imperative mood when issuing orders and commands, thus imposing his/her will on the addressee by trying to get the latter do what is in his/her (i.e. the speaker's) best interest. However, at the same time the English speaker leaves it to the addressee to decide whether to comply with the order or not. In contrast, the indicative mood, especially with the verbs in the past and present tenses, represents things as facts of life. Hence, when the Armenian speaker makes use of the indicative mood when issuing orders and commands, he/she represents the proposition of the utterance as a fact, namely as something that is already being implemented, without taking much care of the addressee's disposition, i.e. whether the latter will actually comply with the order or not. Such kind of orders 
imply even a higher degree of imposition than the ones expressed in the imperative mood.

Though essentially the same in terms of syntactic structure, the Armenian speech act of advice is different from its English counterpart. The latter seems to be more tentative, which is accounted for by different cultural values; namely, the Anglo-Saxon culture discourages interference in other people's affairs, hence the general tendency in English to reduce the use of the explicit performative formula with the verb advise as much as possible. On the other hand, the Armenian culture encourages intimacy, so interference is often viewed positively as a way of showing concern for the other person. Armenian speakers often find it appropriate to make it explicit that they are

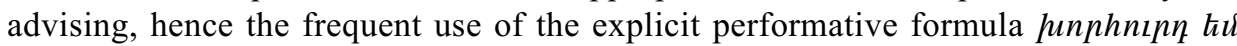
цицL of advice.

By the way, the illocutionary point of the Armenian speech act of advice is often difficult to distinguish from that of warning. To elucidate the point, let us present the semantic structure of the English concept codified in the word warn:

\section{warn}

I say: If you do $X$, something bad may happen to you.

I think: If you know it, you may not do X.

I say this, because I want you to know it.

In Armenian the concept of warning is expressed by the word (Gu/um) qqnızugakl, which, however, differs from the English warn: it implies an assumption that (1) the speaker has authority over the addressee, (2) the speaker intends to protect the addressee from evil, (3) the speaker has some good feelings towards the addressee. Now, in all the three cases the semantic structure of the Armenian speech act of warning could be presented by the following formula:

\section{(Güuu) qqnizugatil}

I say: If you do $X$, something bad may happen to you.

I think: If you know it, you will not do $X$.

I say this, because I don't want you to do X.

Now, if we compare the first component of the Armenian speech act of warning with that of English, we shall see that in both languages the given speech act is issued to warn the addressee against something bad. However, when we come to the second and the third components of warning, which, in fact, reveal the speaker's attitude to the addressee, we shall see a considerable difference between the corresponding acts in the two languages: the English speaker acknowledges the addressee's right for autonomy and self-determination, leaving it to the addressee to choose what is in his best interest or what course of action to take after he has been warned. This particular attitude is best revealed in the use of the modal verb may (If you know it, you may not do X). In contrast, the Armenian speak- 
er feels it his duty or even his right to persuade the addressee to act in such a way as to avoid something bad mentioned in the warning. In this way the Armenian speaker simply tries to impose his will on the addressee. This attitude is best revealed in the use of the modal verb will (If you know it, you will not do X). In this characteristically Armenian behaviour we witness such culture-specific features as intimacy, on the one hand, and interference in other people's affairs on the other. Such an approach on the part of the Armenian speaker may be explained in two possible ways: either the speaker is really concerned about the addressee and feels responsible for him, or the speaker feels he has authority over the addressee and wants to get the latter do what is in his (i.e. the speaker's) best interest. In the former case the illocutionary force of the Armenian speech act of warning is often difficult to distinguish from that of advice, whereas if the latter case is true, we already deal with the speech act of threatening. By the way, just as in English, in Armenian too the illocutionary force of the speech act of warning is often difficult to distinguish from that of threatening. What makes things even more complicated is that the performative formula GuhumqqnızugGnıv $k \mathfrak{u}$ is often used in Armenian to issue threats rather than warnings, which is accounted for by the lack of a performative formula with the verb umunam in Armenian and the verb threaten in English correspondingly. The point is that the concept encoded in the English verb threaten and the corresponding Armenian verb uщшияm is associated with something negative, hence the universal avoidance of its use.

As for the speech act of suggesting, if in English it is often difficult to distinguish from advice, in Armenian such a problem hardly ever arises, for the Armenian speech act of suggesting is mostly of the inclusive-we type and is easily recognized by the specific forms in which it is expressed. To elucidate the point, let us adduce the following examples, taken from different Armenian TV series:

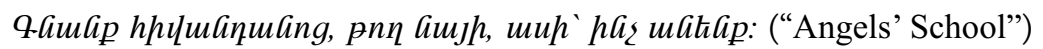 \\ 7h tht'p huikGp hнu ltaugn: ("Revenger")

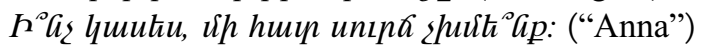

Now, it is easy to see that the first two examples, which represent the commonest grammatical-syntactic means of expressing suggestions in Armenian, correspond to one of the commonest English forms used to perform the speech act of suggesting, namely the Let's do $X$ form. The third example reveals another illocutionary force indicating device for the Armenian speech act of suggesting, which corresponds to the English constructions of the type Let's do X, shall we?, What about doing X?, How about doing X?, Why not do $X$ ? . Observation along this line shows that Armenian speakers very rarely use constructions corresponding to the English Why don't you do X? when making suggestions, for this type of construction tends to be perceived in Armenian as a direct question rather than a suggestion. Hence, what makes constructions of the given type be interpreted as suggestions is rather the context and the speech situation.

To conclude, the basic position we have taken in this article is that the differences between English and Armenian in the sphere of the so-called "indirect" speech acts 
are motivated to a considerable degree by differences in cultural norms and cultural assumptions as well as by different hierarchies of cultural values; the general mechanisms themselves are culture-specific. The choices embodied in individual languages reflect not only "natural logic", and not only a combination of "natural logic" with historical accidents. They also reflect "cultural logic". Thus, what has been discussed within the frames of the given paper asserts the value of investigation of speech acts in illuminating social language interactions and in helping to be rational and choose the course of action which most effectively and at least cost attains the desired end, no matter what our culture-conditioned attitudes, values and purposes are.

\section{References:}

1. Austin, J.L. (1962) How to Do Things with Words. Oxford: Oxford University Press.

2. Austin, J.L. (1971) Performative-Constative. // The Philosophy of Language. J.R.Searle (Ed.), Oxford: Oxford University Press.

3. Bach, K. \& Harnish, R.M. (1979) Linguistic Communication and Speech Acts. Cambridge: MIT Press.

4. Kramsch, C. (1998) Language and Culture. // Oxford Introductions to Language Study. / Ed. by H.G.Widdowson. Oxford: Oxford University Press.

5. Sadock, J.M. (1974) Toward a Linguistic Theory of Speech Acts. New York: Academic Press.

6. Searle, J.R. (1998) Mind, Language, Society: Philosophy in the Real World. New York: Basic Books.

7. Searle, J.R. (1969) Speech Acts - an Essay in the Philosophy of Language. Cambridge: Cambridge University Press.

8. (1980) Speech Act Theory and Pragmatics. / Ed. by J.R. Searle, F.Kiefer, M.Bierwisch. Dordrecht, Holland: Reidel.

9. Wierzbicka, A. (2003) Cross-Cultural Pragmatics: The Semantics of Human Interaction. Berlin/New York: Mouton de Gruyter.

10. Yule, G. (1996) Pragmatics. Oxford/New York: Oxford University Press.

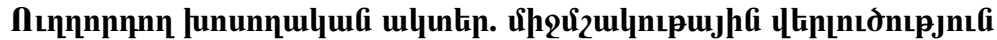

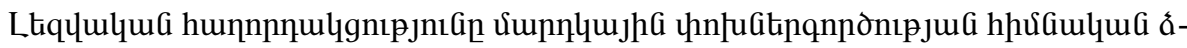

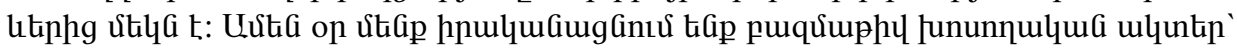

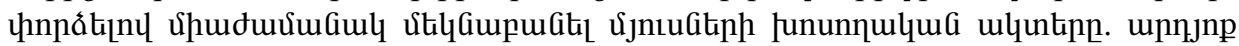

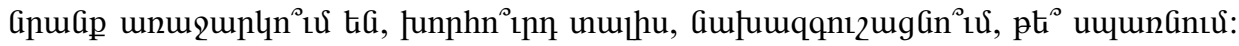

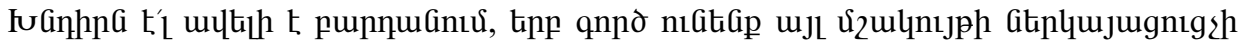

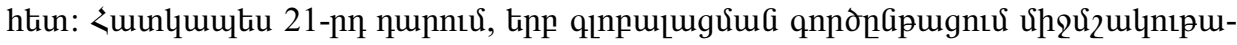

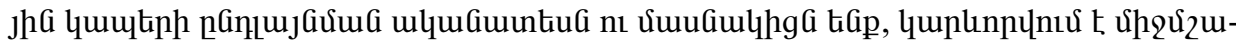




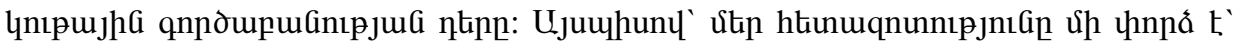

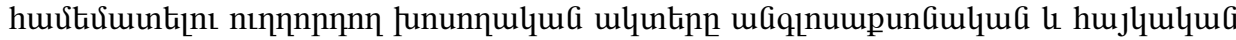

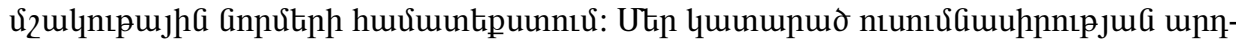

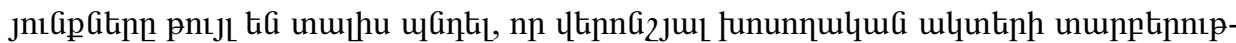

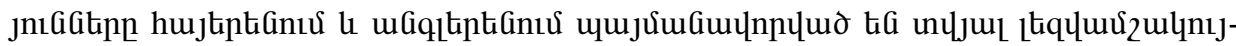

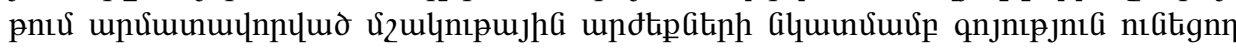
ununptin ltinuptinúnılipgitinnu: 